doso en la 1

ar ejemplos a

is funcionalidac uso, dependiende encarnan los conceptos detr por e $\Lambda$ influ
$\mathrm{Pe}$ infin:

Las formas $d r$ oceso de sig ialidad .

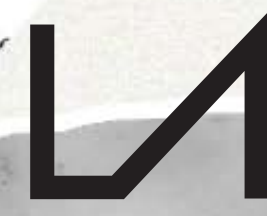

R E V I S A
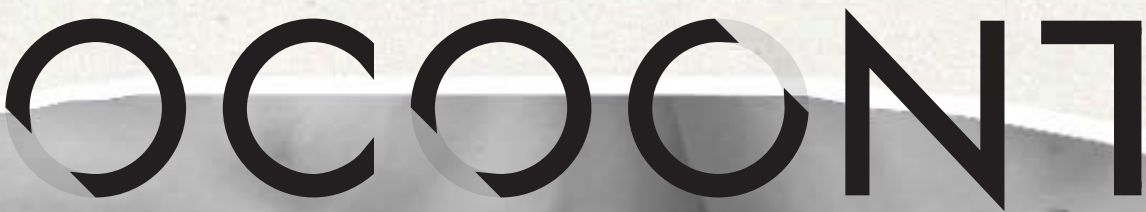

D $E$

No $6 \cdot 2019 \cdot$ ISSN 2386-8449

"El producto del diseñador es un proyecto, el estado previo de un objeto", Entrevista con Norberto Chaves, por Fernando Infante

El papel de la investigación y la teoría en diseño. Una conversación abierta, por Fernando Infante y María Jesús Godoy

UT PICTURA POESIS

Abandonar la escritura. Poesía experimental y manifiesta, Ignacio Gómez de Liaño

PANORAMA: FILOSOFÍA DEL DISEÑO Sección coordinada por Fernando Infante y María Jesús Godoy

Pensar el diseño, Fernando Infante y María Jesús Godoy (Coordinadores)

TEXTOS INVITADOS

Estatus y estado del điseño más allá del objeto, Pedro Medina Reinón

Mar de Nubes, Cuerpo de Cristal, Dionisio González

ARTÍCULOS

Understanding Design Aesthetics beyond Functional Beauty accounts, Lucía Jiménez Sánchez

Estética y diseño industrial: debates y controversias, Joan M. Marín

Del ornamento al delito. El diseño y la sociedad en Charles Baudelaire y Adolf Loos, Jorge López Lloret

When is Architecture not Design? Saul Fisher

Diseño y habitabilidad: una aproximación basada en los lenguajes de patrones, Antonio Hidalgo Pérez

Marcel Breuer: un diseñador global. Experiencias en el ámbito de la vivienda prefabricada, Salvador J. Sanchis, Ignacio Peris y Pedro Ponce Diseño y artes escénicas: el papel de Oskar Schlemmer en Das Triadische Ballett y la actualidad de la Bauhaus, Milagros García Vázquez Lo performativo en prácticas de arte y diseño actuales vinculadas a procesos de innovación social. El caso de La Venezia che non si vede y de La borda, Tània Costa Gomez

Articulaciones de la estética y el diseño. El caso de la evaluación a partir de la investigación dirigida en la carrera de diseño escénico de la Universidad de las Artes de Cuba, Mara Rodríguez Venegas y Xiomara Romero Rojas

SUPLEMENTO

El diseño, la ciudad y un lápiz de labios, Mercedes Espiau, Mar García Ranedo y Alejandro Rojas mas. 


\section{UつCつCNTE}

No $6 \cdot 2019 \cdot \operatorname{ISSN} 2386-8449 \cdot$ DOI 10.7203/LAOCOONTE.5.15381

https://ojs.uv.es/index.php/LAOCOONTE/index

COORDINACIÓN EDITORIAL

Anacleto Ferrer (Universitat de València)

Francesc Jesús Hernàndez i Dobon (Universitat de València)

Fernando Infante del Rosal (Universidad de Sevilla)

SECRETARÍA DE REDACCIÓN

Lurdes Valls Crespo (Universitat de València)

Vanessa Vidal Mayor (Universitat de València)

COMITÉ DE REDACCIÓN

Tamara Djermanović (Universitat Pompeu Fabra), Rosa Fernández Gómez (Universidad de Málaga), Anacleto Ferrer (Universitat de València), Ilia Galán (Universidad Carlos III), Ana María García Varas (Universidad de Zaragoza), María Jesús Godoy (Universidad de Sevilla), Fernando Infante del Rosal (Universidad de Sevilla), Miguel Ángel Rivero (Universidad de Sevilla), Miguel Salmerón (Universidad Autónoma de Madrid), Gerard Vilar (Universitat Autònoma de Barcelona).

COMITÉ CIENTÍFICO INTERNACIONAL

Rafael Argullol* (Universitat Pompeu Fabra), Luis Camnitzer (State University of New York), José Bragança de Miranda (Universidade Nova de Lisboa), Bruno Corà (Università di Cassino), Román de la Calle* (Universitat de València), Eberhard Geisler (Johannes Gutenberg-Universität Mainz), José Jiménez* (Universidad Autónoma de Madrid), Jacinto Lageira (Université Paris 1 Panthéon-Sorbonne), Bernard Marcadé (École Nationale Supérieure d'Arts de Paris-Cergy), Elena Oliveras (Universidad de Buenos Aires y Universidad del Salvador), Pablo Oyarzun (Universidad de Chile), Francisca Pérez Carreño* (Universidad de Murcia), Bernardo Pinto de Almeida (Faculdade de Belas Artes da Universidade do Porto), Luigi Russo (Università di Palermo), Georges Sebbag (Doctor en Filosofía e historiador del surrealismo), Zoltán Somhegyi (University of Sharjah, United Arab Emirates), Robert Wilkinson (Open University-Scotland), Martín Zubiria (Universidad Nacional de Cuyo). *Miembros de la Sociedad Española de Estética y Teoría de las Artes, SEyTA

\begin{tabular}{lll}
\hline DIRECCIÓN DE ARTE & REVISIÓN DE TEXTOS & TRANSCRIPCIÓN DE TEXTOS \\
El golpe. Cultura del entorno & Antonio Cuesta & Álvaro G. Serna
\end{tabular}

(cc) BY Excepto que se establezca de otra forma, el contenido de esta revista cuenta con una licencia Creative Commons Atribución 3.0 España, que puede consultarse en http://creativecommons.org/licenses/by/3.0/es/deed.es

EDITA

\section{SEyTA.}

CON LA COLABORACIÓN DE

\begin{tabular}{|c|c|c|c|}
\hline $\begin{array}{l}\text { VNIVERSITAT } \\
\text { B VALENCIA } \\
\text { Institut te Creativitat } \\
\text { | |nnovacions Educatives }\end{array}$ & $\begin{array}{l}\text { VNIVERSITAT } \\
\text { IE ÖVALENCIA Departament de Filosofia }\end{array}$ & 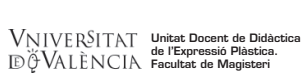 & \\
\hline $\begin{array}{l}\text { DEPARTAMENTO DE ESTÉTICA } \\
\text { E HISTORIA DE LA FLLOSOFIA }\end{array}$ & $\frac{\text { UAW }}{\frac{\text { UNIVRSSIDAD AUTONOMA }}{\text { DE MADRID }}}$ & $\begin{array}{l}\text { Universitat Autònoma } \\
\text { de Barcelona }\end{array}$ & $\begin{array}{l}\text { VNiVERSiDAD } \\
\text { Departamento de Filosofia, Lógica y Estética }\end{array}$ \\
\hline
\end{tabular}

LAOCOONTE aparece en los catálogos: 


\section{LつCつCN7E}

"Cuanto más penetramos en una obra de arte más pensamientos suscita ella en nosotros, y cuantos más pensamientos suscite tanto más debemos creer que estamos penetrando en ella".

G. E. Lessing, Laocoonte o los límites entre la pintura y la poesía, 1766.

Vo hay cól.

létodo, de pen.

:ión en general. Ith

zar la forma para el $\mathrm{n}$.

eptual por las orígenes

la, el objeto, la exposición

storia, porque existe en el $\mathrm{m}$

das sus raíces. Desde alli cc _. panoram

n conceptual y donde el émencia del con 'iseñado, como es el a al objeto y el di $\begin{array}{ll}\text { igen } \mathrm{de}^{\text {to }} \text { la inmer } & \text { tolvidada, o comc } \\ \text { trozo de madera ar }\end{array}$ a manera dorm comunicar ene nundo. Seguin? sngo en manos te el método $C$ les. A partir c teria prima $\mathrm{p}_{\mathbf{c}}$

'xto se puede:

¿ño, en proyea

amientos de $\mathrm{u}$

a conscie-

.)

en la publicación jue "plos de la impor te las nalidades porqu ura un ${ }^{2}$ diendo de qui zenerar $\mathrm{u}$ ción de nr? lne

in-

n-

is.

le http:,

le crear visualidades. A partir de.

ellas la propia materia prima para un en que desde un texto se puede generar $u_{11}$ i

Pensar en diseño, en proyección de nue

posibles comportamientos de una colecti

presente como una consciencia del hecho que estamos elaborando, significac

nuestro entorno (..)

Cardoso, R. C. Rafael. (2014). Design para um mundo complexo. Sãc asil: Cosac Naify. 


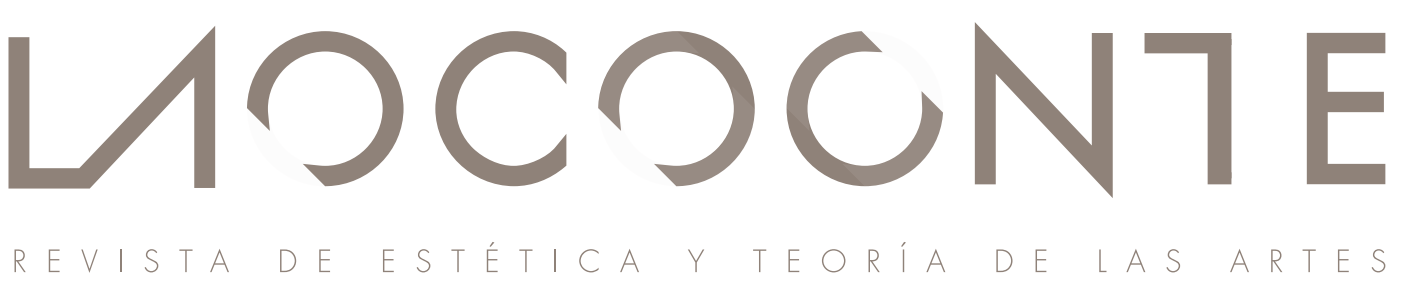

$\mathrm{N}^{\circ} 6 \cdot 2019$

PRESENTACIÓN

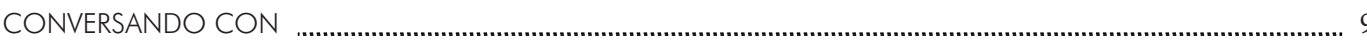

"El producto del diseñador es un proyecto, el estado previo de un objeto", Entrevista con Norberto Chaves,

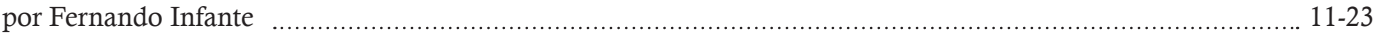

El papel de la investigación y la teoría en diseño. Una conversación abierta, por Fernando Infante

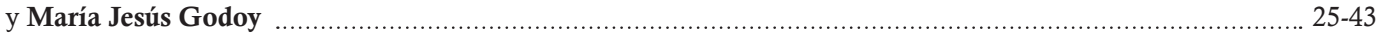

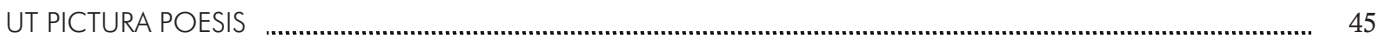

Abandonar la escritura. Poesía experimental y manifiesta, Ignacio Gómez de Liaño ................................................ 47-95

Imágenes de Laocoonte n. 6, de Isadora Gonzaga ................................................................................................... 96-97

PANORAMA

FILOSOFÍA DEL DISEÑO

Pensar el diseño, Fernando Infante y María Jesús Godoy (Coordinadores) .............................................. 101-105

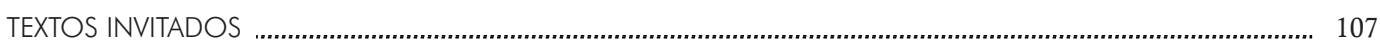

Estatus y estado del diseño más allá del objeto, Pedro Medina Reinón . ................................................... 109-125

Mar de Nubes. Cuerpo de Cristal, Dionisio González .............................................................................. 127-133

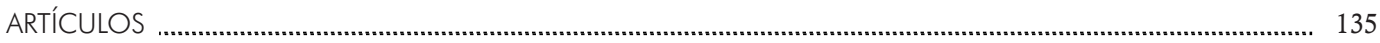

Understanding Design Aesthetics beyond Functional Beauty accounts, Lucía Jiménez Sánchez ................. 137-149

Estética y diseño industrial: debates y controversias, Joan M. Marín _...................................................... 150-164

Del ornamento al delito. El diseño y la sociedad en Charles Baudelaire y Adolf Loos, Jorge López Lloret ... $165-182$

When is Architecture not Design? Saul Fisher ……............................................................................. 183-198

Diseño y habitabilidad: una aproximación basada en los lenguajes de patrones, Antonio Hidalgo Pérez ...... 199-215

Marcel Breuer: un diseñador global. Experiencias en el ámbito de la vivienda prefabricada,

Salvador José Sanchis, Ignacio Peris y Pedro Ponce

Diseño y artes escénicas: el papel de Oskar Schlemmer en Das Triadische Ballett y la actualidad de la Bauhaus, Milagros García Vázquez

Lo performativo en prácticas de arte y diseño actuales vinculadas a procesos de innovación social.

El caso de La Venezia che non si vede y de La borda, Tània Costa Gomez

Articulaciones de la estética y el diseño. El caso de la evaluación a partir de la investigación dirigida en la carrera de diseño escénico de la Universidad de las Artes de Cuba, Mara Rodríguez Venegas

y Xiomara Romero Rojas

SUPLEMENTO 
Walter Gropius. La vida del fundador de la Bauhaus, Jorge Martínez Alcaide

¿Qué significa pensar la política desde la estética? Àger Pérez Casanovas

Ideologías estéticas en los orígenes de la pintura moderna, José Luis Plaza Chillón 300-303

Sobre a estética, Luis Carlos Pereira

Músicas populares. Sociedad y territorio: Sinergias entre investigación y docencia, Mar Aleixandre Badenes.

307-309

La necesidad de la mirada antropológica sobre la literatura, Pablo de Benito David

A propósito de Chandler, o la novela policíaca como tratado filosófico, Juan Evaristo Valls Boix

Videre aude!, Anacleto Ferrer

La inaplazable memoria del dolor y el sufrimiento, Antonio Notario Ruiz

La alargada sombra de la pintura, Raquel Baixauli

Sondear la maravilla, Juan Evaristo Valls Boix

... Y lo sabes, Marc Hernández Montoro

Arqueologías de la modernidad en las artes. Ensayo estético, Carlota Fernández-Jáuregui Rojas

Estética de la Instalación, Luis Cemillán Casis

La Herencia de otra época, María Jesús Godoy Domínguez

Del Theatrum Mundi al Gran Vidrio, Miguel Salmerón Infante

Imágenes de Isadora Gonzaga.

Fotografía de portada de Tamara Djermanovic intervenida por Isadora Gonzaga.

Los coordinadores de la sección Panorama: Filosofia del diseño agradecen

a Antonio Molina Flores su colaboración. 
ner.

llobj vidada, o de ma la publica. los de la im nalidades po ndientn $\mathrm{A}$ -
, la

que e.

usdño, si nn

ज. " da yara el mu tual y d

or enc or las orígenes un tmo, fía del diseño,

rpintero que'curra la forma de

eña Desige para un mundo complexo, de los bienes producidos por el hombre :tores subjetivos también influyen en su

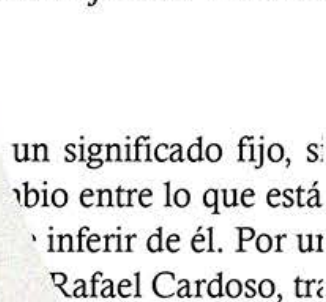

Rafael Cardoso, tri

No hay cómo no e método, de pensa 1, donde la reación en geperal. salizar la forma pa. rue amb ${ }_{\text {Snceptual por }}{ }^{1}$

$$
\text { -rola ol } n^{\prime}
$$

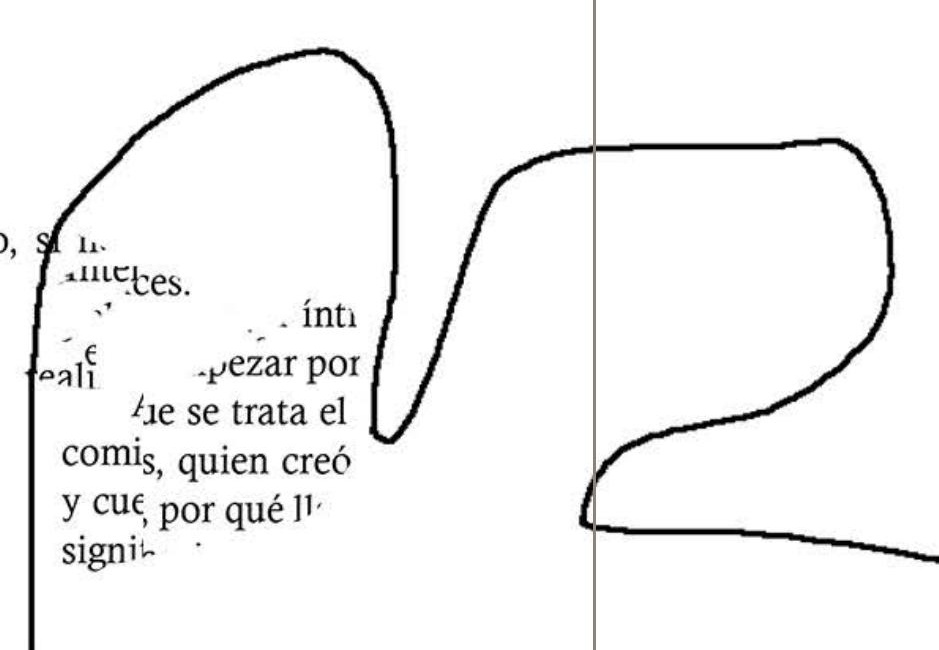

LOCOCNTE

PANORAMA: FILOSOFÍA DEL DISEÑO

Fernando Infante del Rosal y María Jesús Godoy Domínguez

(Coordinadores) 
¿s raír

„ue exir' e es, qui

a concrablot

i ser dica'oniunte

sol

has un us

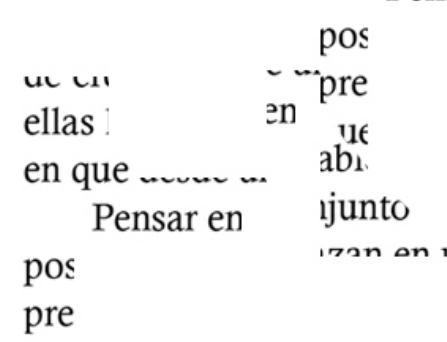

tus

art

ma
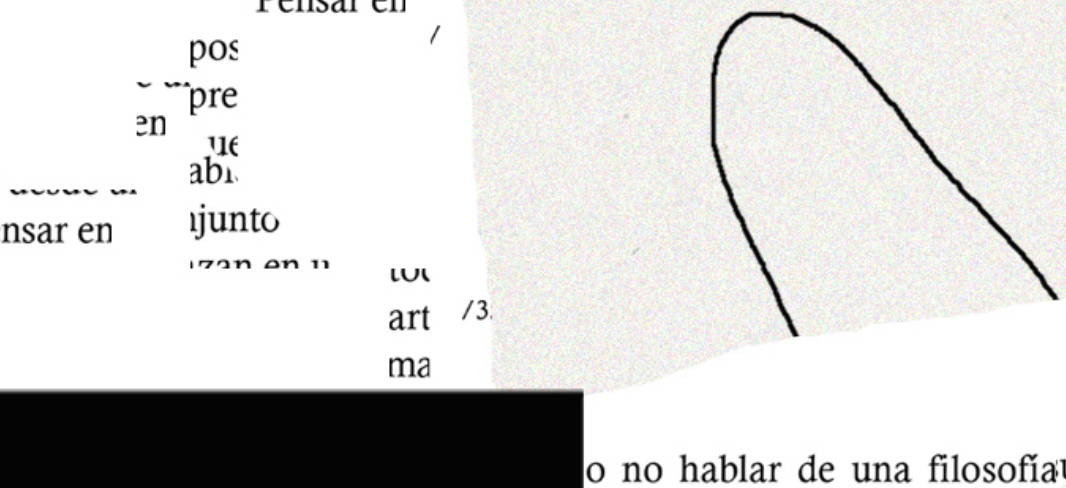

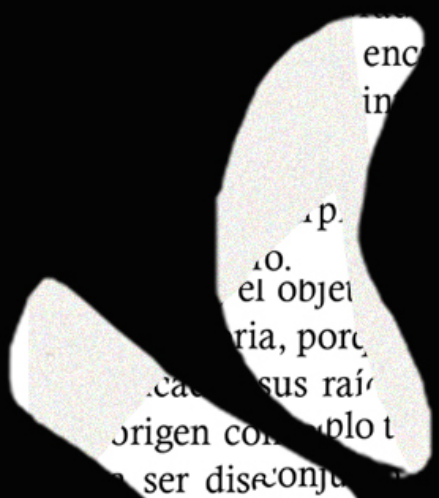

ser disfionj

seventrelazar

Pensa

nfinitame

contrar su.

hacex conscien

de las mas de

hago

?cié

lo que

presente

ralidades.

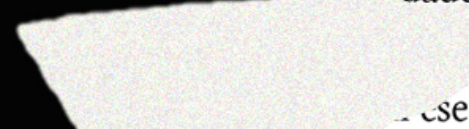

$\rightarrow$ ras que $c$

nenge, para
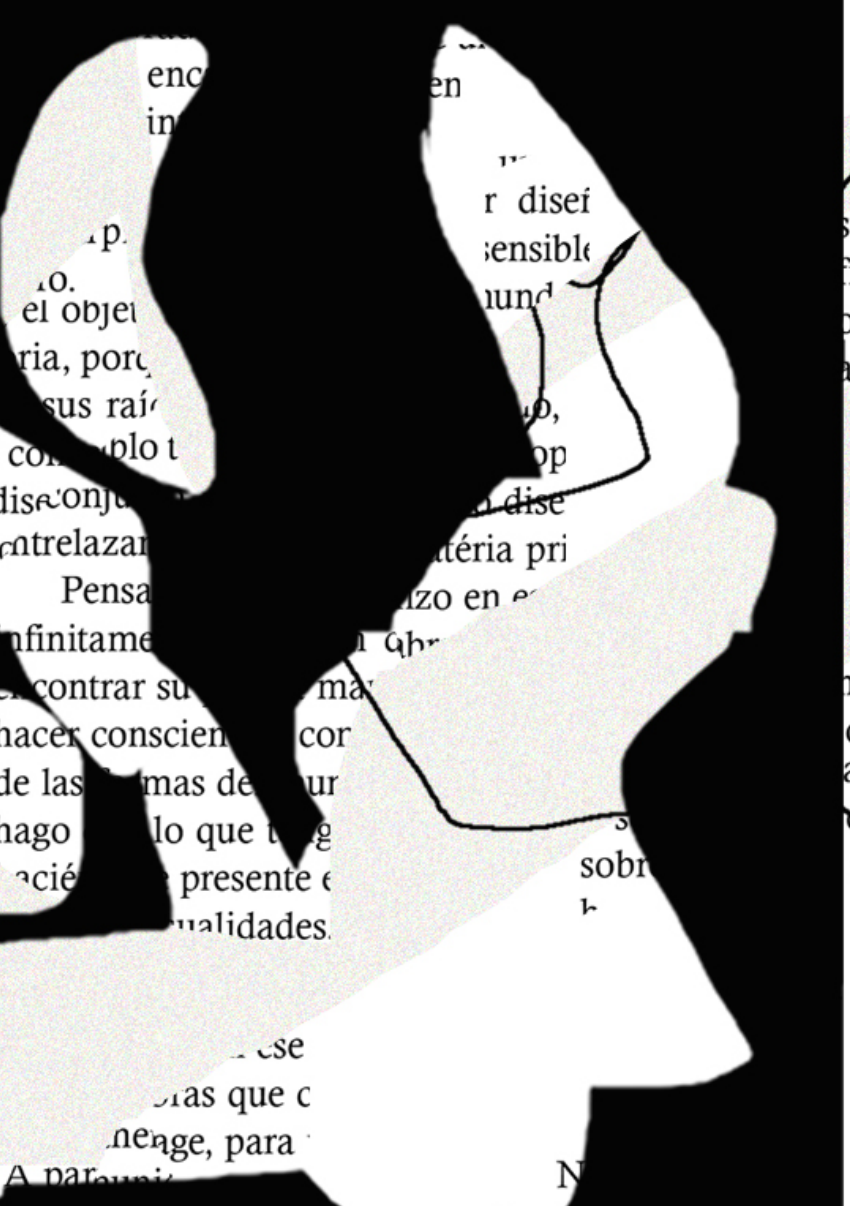

nov

o no hablar de una filosofiav

$\mathrm{Cr}$ Intentaré exponer

rea. el mundo :-

concenes

novg'

su histc.

incadas $s$ '

prigen

a.

ungiv,

do sensibleíaa

o el hilo den carp.

al y urn Curfo.

semo es el panor ma 1

intyanencia del doncep

objeto y el diseñado.

como un carplo

'sa amorfo.

$\eta$ brasileñ ${ }_{\text {no }}$ tier ${ }^{\text {to }}$,

tancia de $e_{\text {el int }}{ }^{\text {irtir de }}$.

No hay cómolos factienc .ma para $\mathrm{u}$ de método, de penso use: $c^{2}$ puede gene creación en general. 1.

en proyección realizar la forma para $\epsilon_{\text {tier }}$ conceptual por las orígs entos de una novela, el objeto, la exr su historia, porque exir.

"cadas sus raír

, en pro para um 1

ientos fincadas sus

origen 
-.iuso.

er el diseño y ?

.tgen de nuestro $\mathrm{m}$

spia manera de constr

nte y comunicar el pro

/351/

lel diseño, si no hablr

in formon. of 1

nror en dir.. o.

hace s

descifra ᄂ.

vos is snli,

351/

'To hay cómo

'n de ne
UOCOCNTE

PANORAMA: FILOSOFÍA DEL DISEÑO

TEXTOS INVITADOS

\section{in}

rar 1

de

col

hech ae metuuu, -

creación en ger

realizar la form

conceptual por

novela, el objet

su historia, por

fincadas sus ra

origen concept

a ser diseñado.

sobrevolando 1

hace surgir la $\mathrm{f}$

descifra una ler

y se la aplica a 
¿s raír

$$
\text { yue exirs a es, qui }
$$

a concrablot . Sor dica'oniunte

sol

has un us

un un

ellas

en que

Pensar en pos

ellas: $\quad$ en pre

en que

Pensar en

pos

pre

il tus

art

ma

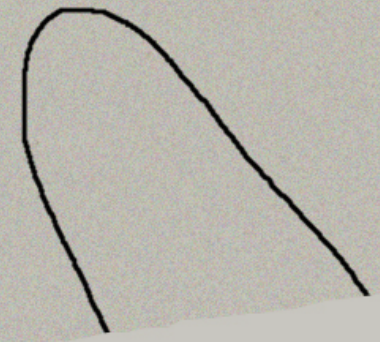

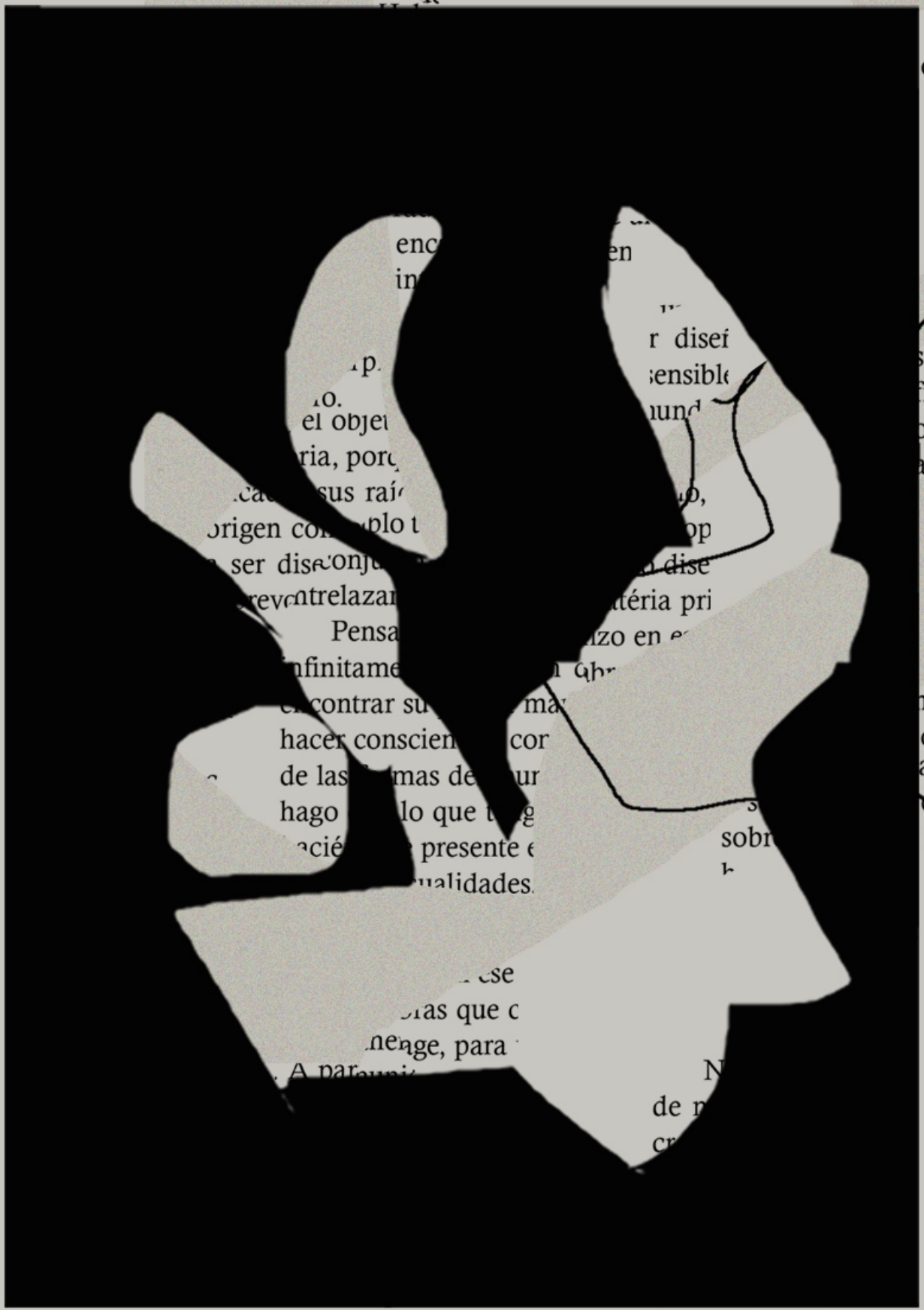

, en pro para um 1

ientos fincadas sus

origen

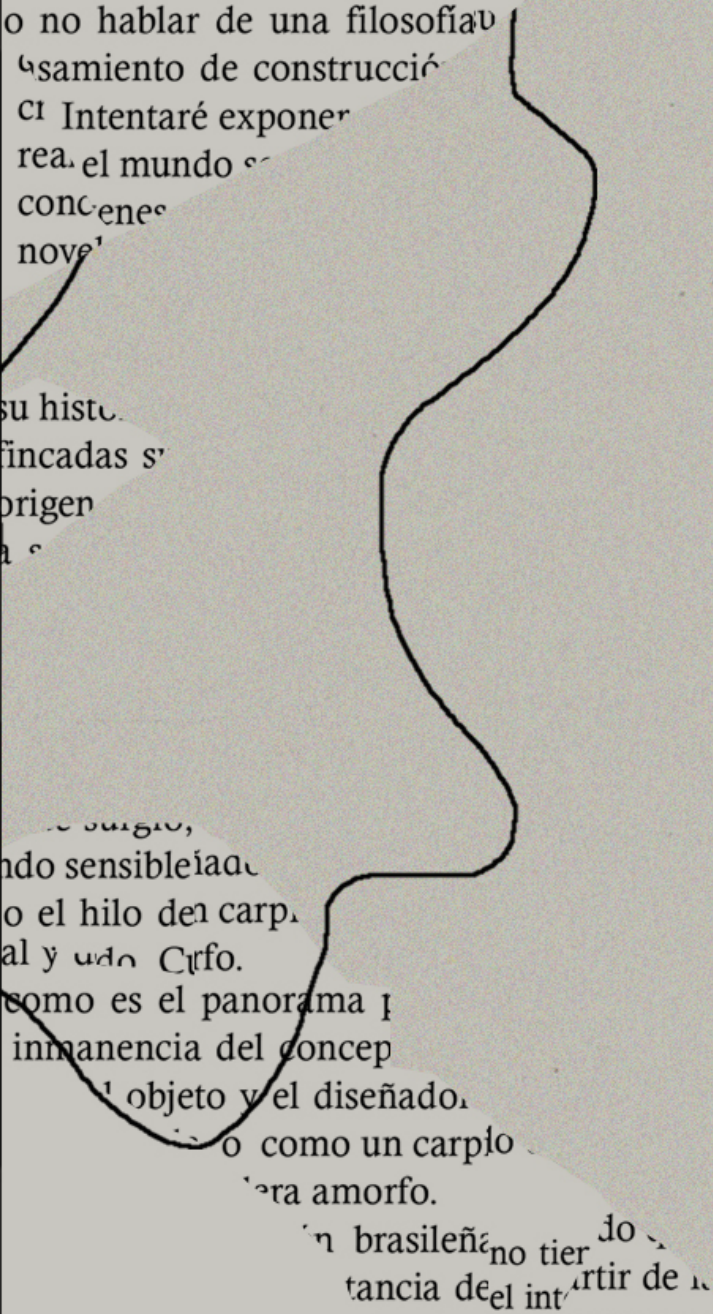

No hay cómolos factienc -ma para $u$ de método, de penso use: $\mathrm{c}^{2}$ puede gene creación en general. 1. en proyección realizar la forma para $\epsilon_{\text {tier }}$ conceptual por las oríg $\epsilon^{-}$ novela, el objeto, la exr $\mathrm{F}_{\mathrm{e}}$, su historia, porque exir

" ncadas sus raír

v concrablo también de fael. (2014). a'onjunto con la for

1azan en un comná 


\title{
Estatus y estado del diseño más allá del objeto ${ }^{1}$
}

\section{Status and state of design beyond the object}

\author{
Pedro Medina Reinón ${ }^{*}$
}

\begin{abstract}
Resumen
Históricamente el diseño no ha construido un discurso autónomo, definiéndose en relación con otras disciplinas como las artes visuales. Así, se ha caracterizado por un valor de uso, por ser un producto industrial y por su pertenencia a una cultura del proyecto. Establecer el debate en estos términos reduce la complejidad del mundo del diseño y lo remite a un discurso objetual que no corresponde al paradigma actual, marcado por la desmaterialización producida como consecuencia de la enfatización del diseño como proceso, la aparición de dinámicas colaborativas, su transformación en método y la generalización de prácticas determinadas por las nuevas tecnologías.
\end{abstract}

Palabras clave: Diseño, arte, cultura del proyecto, design thinking, colaboración.

\begin{abstract}
The design has not built an autonomous history, defining itself in relation to other disciplines such as the visual arts. Thus, it has been characterized by a use value, because it is an industrial product and its belonging to a project culture. Establishing the debate in these terms reduces the complexity of the design world and refers it to an object discourse that does not correspond to the current paradigm, defined by the dematerialization produced as a consequence of the emphasis on design as a process, the emergence of collaborative dynamics, the consideration of design as a method and the generalization of practices determined by new technologies.
\end{abstract}

Keywords: Design, art, project culture, design thinking, collaboration.

\section{Arte y diseño}

\section{En torno a discursos objetuales}

"El diseño nunca ha tenido una historia autónoma. Ha sido siempre considerado como parte de la cultura industrial, como ornamento social o como un aspecto curioso de la historia de las costumbres". ${ }^{2}$ Estas palabras se hallan al inicio del número de los Cuadernos de Diseño dedicado a la relación entre arte y diseño, y señalan un hecho

1 Tengo una deuda excepcionalmente grande con los integrantes de las numeras audiencias que oyeron versiones anteriores de este artículo, algunos de los cuales ya no lo reconocerán debido a los cambios radicales que sus observaciones inspiraron. Estoy particularmente agradecido a Paloma Atencia Linares, Jiri Benofsky, Diarmuid Costello, and Martin Steenhagen, quienes me proporcionaron comentarios por escrito; y a Alfred Archer, Al Baker, Cat Saint Croix, David Davies, Daan Evers, Dominic Gregory, Margaret Iverson, Dominic Lopes, Aaron Meskin, Ludger Schwarte, Michael Stynes, Kendall Walton, Alan Wilson, and Dawn Wilson.

2 Jarauta, F. 2006, p. 11.

* Istituto Europeo di Design, Turín (Italia).pedromedinareinon@gmail.com 
que condiciona el estatus del diseño: su dependencia de disciplinas anteriores para definirlo.

A ello se podría añadir -con Gillo Dorfles- que "la ambigua relación entre artes visuales y diseño se representa una y otra vez de forma intermitente", ${ }^{3}$ lo que indica un estado de "negociación" permanente, cruces e intercambios que cada vez son más frecuentes. Siendo así, y para evitar extender la lista de referencias, de William Morris a Tomás Maldonado, pasando por tantos otros, se puede completar este acercamiento a la falta de autonomía del diseño y su especificidad con algún clásico más, como Giulio Carlo Argan, cuando en 1972 manifestó la frontera entre los dos ámbitos creativos:

Se concede al artista cualquier licencia (...) siempre que no salga del círculo cerrado de una técnica que gira sobre sí misma. No se le permite proyectar, porque el proyecto no nace del consenso o del disenso, sino del análisis crítico de la situación (...) no se limita a reflejar el estado de las cosas, sino que interviene con una metodología rigurosa (...) El proyecto, precisa estructuras y formas, es siempre un acto estético, es diseño. $^{4}$

Esta cita establece la discusión en torno a un aspecto importante: la pertenencia o no del arte a una "cultura del proyecto", a la que sí pertenece el diseño; y su reconocimiento como acto estético, es decir, de fondo Argan tiene presente cierta "muerte del arte" cuando el valor se desplaza de la obra artística al objeto de uso. A estas características se pueden asociar otras como el carácter industrial -y, por tanto, serial y reproducible- del diseño y la concepción idealizada del arte como creación pura y sin función.

Esta posición, que tiene la funcionalidad como aspecto crucial, tiene evidentemente en su base el principio del "desinterés" como característico de la creatividad artística. Una noción que parte de Shaftesbury, pero que tiene como principal referencia la Crítica del juicio de Kant, ${ }^{5}$ que sitúa el juicio estético en otra esfera bien distinta de la que concierne a la utilidad. Una de sus derivas la hallamos en Adolf Loos cuando opone arte y utilidad al pensar que cualquier cosa que tenga una finalidad concreta está excluida de la esfera del arte.

Para abordar esta supuesta frontera entre los dos ámbitos creativos, puede ser significativa la figura de Bruno Munari, hoy día reconocido tanto en el ámbito del diseño como en el de las artes visuales. ${ }^{6}$ No obstante, ya desde joven marcó distancias entre ambos universos desde un punto de vista metodológico, que enlaza con la citada cultura del proyecto y, en algunos aspectos, con posicionamientos anteriores como el de Herbert Read, para quien no se debía adaptar la producción industrial a los cánones estéticos de la artesanía o del arte, sino adquirir una identidad propia y, por tanto, crear nuevos principios estéticos para nuevos métodos productivos y nuevos esquemas proyectuales. ${ }^{7}$

Munari da su punto de vista en muchas ocasiones sobre esta especificidad del proceso creativo del diseñador, si bien la referencia principal es Artista y diseñador, que

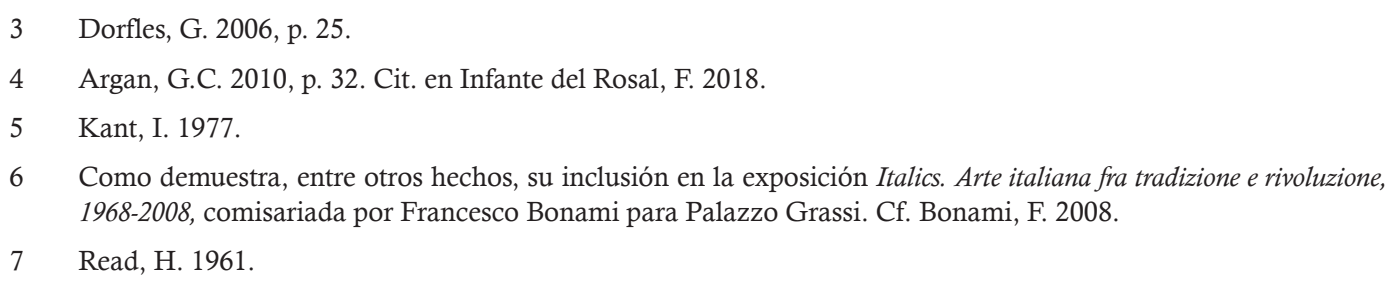


al inicio de los setenta fue un reconocido homenaje y reivindicación de la profesión de diseñador, distinta de la imagen del artista romántico. A esta figura opone el "diseñador objetivo", que viene caracterizado como "proyectista" que atiende al aspecto industrial, estético y político de aquello que crea, como perteneciente a una comunidad. En efecto, de modo muy sintético, la diferencia residiría en que el diseñador, a diferencia del artista, trabaja en grupo, no tiene estilo, resuelve problemas, inventando soluciones neutras y anónimas, y no produce obras de arte sino objetos funcionales, a través de un método específico dentro de un sistema objetivo. ${ }^{8}$

Aquí hay una definición neta de la particularidad del trabajo del diseñador, pero ni que decir tiene que esta concepción del arte está anclada en su momento histórico y político, diferenciándose de un tipo de artista que no corresponde con muchos comportamientos artísticos del último medio siglo, ligado a prácticas de corte político y procesual, ni tampoco con la realidad actual del diseño, que en buena parte está dominada por un star system donde el estilo del diseñador es reconocible y es parte del valor comercial del objeto, entendida dentro de un discurso sobre identidad y marca.

Aun así, sitúa la discusión en un punto recurrente cuando se destacan características propias del diseño, como la "funcionalidad" -y la eficacia que se deriva de la misma-, estableciendo una distancia entre valor de uso y valor estético, que se relaciona también con la activación de un proceso proyectual a partir de un cliente. Pero esta diferencia se basa en una concepción ideal del arte, que ignora buena parte de la historia del arte, repleta de comitentes, que con frecuencia encargaban las obras con el objetivo de mostrar su poder, rememorar un evento o personaje histórico o incluso educar a través de imágenes a un pueblo analfabeto.

Pero volviendo a Munari, se ha de señalar que el núcleo de su razonamiento se encuentra en el capítulo Fantasía y creatividad, siendo el artista quien trabaja con la primera y el diseñador con la segunda, una volcada a la pura ideación y la otra a un sentido práctico. Cabe preguntarse si la contraposición es tan neta y si el propio Munari trabajaba encorsetado en uno de estos ámbitos sin pasar al otro, incluso sirviéndose del mismo método. Habría que recordar las variaciones sobre los Tenedores parlantes, que son formas de diversión -un elemento esencial en Munari-que diseñó "sin ningún fin práctico, solamente para jugar con la fantasía", modificando los objetos de uso con humor, para huir de las lógicas del comportamiento cotidiano. ${ }^{9}$

En efecto, es fácil caer en contradicciones cuando se es tan drástico, por no decir que en su libro sobre el diseñador se coló un capítulo que, en el fondo, es un elogio de la fantasía. De esta forma, la síntesis de la obra del propio Munari podría ser la siguiente: "Transfiere la fantasía en la creatividad, la ordena, la organiza y la transforma en método. Es un fantasista creativo, como es evidente en otro libro, Fantasía, que corrige parcialmente Artista y diseñador".${ }^{10}$ Lo que queda entonces es la potencialidad del "hacer", que no destierra las características estéticas del objeto y permite dos tipos de aproximación a los objetos, no necesariamente inconciliables, lo que convertiría al

8 Cf. Munari, B. 1971. El método: problema - definición del problema - componentes del problema - recopilación de datos - análisis de datos - creatividad - datos sobre materiales y técnicas - experimentación - modelos/ prototipado - verificación - dibujos constructivos - solución.

9 Cerritelli. C. 2017, p. 38. Un divertissement en el que insiste Gillo Dorfles como elemento fundamental de la obra de Munari, cf. ibíd., p. 43.

10 Vitta, M. 2018. 
propio Munari en "el eslabón perdido entre Moderno y Postmoderno, en el paso del racionalismo de forma-función al decorativismo subversivo de Memphis, pero también al anti-Sottsass (...) [para quien] la emoción va antes de la función; para Munari, al contrario, la función crea la emoción". ${ }^{11}$

Ya ha aparecido una palabra muy importante para el diseño actual -incluso el más eficaz-, que es "emoción", como complemento de la funcionalidad. En efecto, la reivindicación del "buen hacer" remite a otro ámbito: el del artesano, ${ }^{12}$ que, en líneas generales, enfatiza el valor positivo del Bau-kunst (arte de construir), entendido como saber hacer que aúna conocimiento técnico y construcción fundados en la aptitud. Esta es una premisa que también debe perseguir el diseñador, pero con diferencias: el diseñador lleva a cabo el tránsito que va del utensilio a un objeto que busca también un goce estético más allá de la utilidad, lo que supone la aparición de un nuevo sector profesional que se situó entre las "bellas artes" y la artesanía tradicional.

Por tanto, aquí reside su diferencia, que se suma a su carácter industrial, que supone una "estética tecnológica" no asimilable a artes aplicadas del pasado, de ahí que una vez más se reivindique como realidad diferenciada, nueva y paralela a otras disciplinas artístico-técnicas. ${ }^{13}$ Además, desde un punto de vista ontológico, el objeto de diseño posee dos características fundamentales: es producido en serie y -así como ocurre con la arquitectura o corrientes del arte actual-experimenta una distancia entre ideación y ejecución, que afecta a aspectos cruciales como la autoría.

De hecho, el diseño rompe con la técnica constructiva tradicional en su orientación a la reproducción en la era de la industrialización y la máquina, lo que conlleva unas características prácticas y estéticas derivadas de la misma que de nuevo marcarían distancias con el arte, debido a la pérdida de "aura" en sentido benjaminiano. ${ }^{14}$

En efecto, esta es una cuestión fundamental dentro de la estética del diseño, pues está vinculada a la tecnología y ligada al principio de "montaje", que podría suponer la muerte de la creación artística -o al menos la limitación de la "autoría demiúrgica", compartida colectivamente- y su larga exclusión de la institución museo al no tratarse de obras únicas. Es lo mismo que ha ocurrido con otras artes reproducibles como el cine y la fotografía, pues - para Benjamin- la tecnología ha cambiado nuestra forma de ver y, por ende, nuestra forma de valoración estética, perdiendo el "aura" de autenticidad y unicidad espacio-temporal y, por ello, su valor cultual, sustituido por uno expositivo destinado a las masas y a cambiar la cotidianidad. Esto puede entenderse como una característica que "degrada" toda arte reproductiva, pero, por otro lado, también revela su contemporaneidad, a la luz de valoraciones sobre el arte de masas como arte de nuestro tiempo en autores como Juan A. Ramírez. ${ }^{15}$

Históricamente es la Gran Exposición del Palacio de Cristal de Londres en 1851 cuando se constata públicamente el paso de la artesanía al diseño. En este evento se mostraron las novedades industriales de la modernidad y un fenómeno fundamental: la dimensión estética del objeto de uso, con el que no estaría muy de acuerdo Loos,

11 Ibíd.

12 Sennett, R. 2009.

13 Dorfles, G. 1959.

14 Benjamin. W. 1992.

15 Ramírez, J.A. 1997 
pero que resultará fundamental para situar el debate en torno a la "forma de lo útil", el "estilo" o la "estética práctica", entre otros conceptos asociados. ${ }^{16}$

En este camino de liberación de la artesanía, el diseño ha pasado por varios períodos: uno donde el binomio forma-función era el eje; la subversión de este "calvinismo estético" por formas radicales y abiertas a lo estético; y un período donde la relación forma-función convive con una recaída en el decorativismo y la afirmación de un diseño lúdico ${ }^{17}$ y emocional. ${ }^{18}$

Por último, otro dato sobre la voluntad de escindir arte y diseño cuando se observan conceptos tan presentes en la actualidad como el de "innovación". Si acudimos al origen etimológico de la palabra (lat. innovatio, -nis), este in-novus implica un "entrar en lo nuevo". La innovación -frente a un "dar origen" de la supuesta "creación pura artística" - es definida como la "creación o modificación de un producto, y su introducción en un mercado", ${ }^{19}$ lo cual nos remite a un producto (no a una idea), no siempre creado, sino también modificado, y dentro del sistema, es decir, en referencia al mercado.

De nuevo, estas consideraciones caen en la esfera de un funcionalismo entendido como praxis, que depende de un alto conocimiento técnico, frente al privilegio de una subjetividad creadora, que aún idolatran algunos epígonos románticos. Si mantenemos una diferenciación entre un ámbito de creación y otro de innovación, se muestran dos caminos que estarían escindiendo las artes del diseño, sobre todo si lo entendemos como la mejora de algo preexistente; sin embargo, de forma similar a lo que ocurría con Munari, ¿no se trata de una reivindicación más corporativa que real a la hora de analizar la metodología y resultados de toda forma creativa dentro del sistema actual? Sobre todo en un momento como el actual donde las derivas del diseño son muy diferentes y donde conviven tendencias como la colaboración con la artesanía, la creación colectiva y la digitalización de los procesos, que nos obligan a replantear cuáles son hoy las características fundamentales del diseño.

Además, se ha de considerar que la realidad industrial en la base de las teorías nombradas - por no hablar del tipo de arte aludido, como si no existieran corrientes conceptuales y éticas dentro del mismo- remite a una condición básica: su carácter objetual. Pero reducir el diseño a diseño de objetos resulta una argumentación falaz, sobre todo desde el punto de vista del presente. Un balance de este breve recorrido en torno a la ambigua relación entre arte y diseño podría ser el siguiente:

- Bajo esta concepción aún objetual, la mayor parte de las teorías clásicas consideran el diseño como diseño de producto, lo que no abarca todas las disciplinas del ramo, como el diseño gráfico o algunas más recientes como el diseño de servicios.

- Se observa que limitar un objeto de diseño a una función específica o a puro styling no encaja en la amplitud y complejidad actual; y menos limitarlo a su relación con conceptos como creatividad o al carácter meramente funcional de la obra. Es justo con la llegada de formas más abiertas y vinculadas a un resultado emocional cuando el valor de uso y el valor estético se complementan y son relevantes para juzgar si una obra está lograda o no.

16 Mecacci, A. 2012. En efecto, Dorfles definió en varias ocasiones el horizonte táctico de la cultura del proyecto bajo una exigencia estética; cf. Dorfles, G. 2010.

17 Dorfles, G. 2006, p. 26.

18 Norman, D.A. 2005.

19 RAE. 
- Además, el carácter objetual en el que se ha establecido el debate no considera la dimensión comunicativa que tiene toda obra; algo obvio en diseño gráfico, y que puede adquirir también un valor simbólico, como ocurre con parte de la arquitectura. Pero en conjunto -como advertía Dorfles $-^{20}$ el juicio estético es necesario para discriminar si algo es verdaderamente artístico y si lo lúdico o lo espectacular no se han impuesto, cegando nuestro gusto.

- Todo ello conduce a una discusión sobre la actual "cultura del proyecto", y sobre todo a pensar si la pregunta no se ha estado formulando desde el lado equivocado. Quizás la cuestión no es si el diseño es artístico o no, sino si las artes visuales actuales pertenecen a una cultura del proyecto, incluida la metodología que esta implica. Parece difícil que no sea así, si se quiere responder a un panorama como el actual, donde la complejidad de prácticas, contextos y procesos requiere otro tipo de acercamiento al sistema creativo.

\section{Cultura del proyecto y sistema del arte}

La palabra "proyecto" ha sido vinculada a un método y una finalidad, donde el carácter estético del diseño está condicionado por estos. Además, también se han de tener en cuenta otras dimensiones del proyecto como la social (transformación efectiva del mundo) y económica (vinculada al mercado y al capitalismo), que resumiría la frase del Premio Nobel de Economía en 1978, Herbert Simon: "Diseñar es cambiar las situaciones existentes en otras más deseables". ${ }^{21}$

Si bien todas estas facetas del diseño deben contar, se ha observado una evolución histórica en la que, además de un efecto sobre la realidad, hoy se tienen en cuenta muchos aspectos a la hora de proyectar algo: se piensa en un diseño al gusto del usuario, recordando que un buen diseño debe ser fácil de utilizar, ha de ser accesible y ha de potenciar la ecoeficiencia, el uso de energías alternativas y materiales sostenibles.

En realidad, estas características podrían aplicarse a la artesanía, de la que ya se confirmó su independencia formal e industrial, y también a otras culturas del proyecto, como la ingeniería, reina del ámbito del "problem solving", aunque hay que matizar que sus soluciones están basadas en habilidades analíticas y matemáticas, frente a una parte más formal, imaginativa y estética que se le presume al diseñador.

Para acercarnos a la definición del ámbito de creación del diseño hoy, se debe enfatizar un aspecto que afecta también a las artes visuales y la ingeniería: la centralidad del proceso, por encima del resultado final, para juzgar el grado de excelencia de la obra, a la luz de problemas de corte ético en la producción y en el mantenimiento del proyecto, además de la relación central con los usuarios, desterrando todo ello la creencia en el objeto terminado como si fuera una escultura sin tiempo.

Este cambio de enfoque, que está relacionado con una transformación de la esencia del diseño y de sus prácticas, puede ser iluminado por evoluciones que el mismo mundo del arte experimentó a finales de los sesenta en torno a la entidad de la obra de arte, y que afectan al análisis de la relación entre la idea y su realización, la enfatización del rol activo del espectador o el fomento del proceso, ${ }^{22}$ entre otros aspectos.

20 Dorfles, G. 2006. Cf. ídem 1959 e ídem 1962, donde trata la dimensión comunicativa formal del objeto industrial, hablando de "consumo simbólico" no tanto del objeto como tal, sino de su imagen.

21 Simon, H.A. 1996, p. 111.

22 Cf. Medina, P. 2014. 
Así, igual que Lucy Lippard anunció en 1973 "la desmaterialización del objeto artístico" 23 en relación con la irrupción del arte conceptual, quizás podamos anunciar ahora algo similar para el diseño, desvinculado de una concepción meramente objetual. En el caso de Lippard, vinculaba este fenómeno al cuestionamiento de los ámbitos tradicionales de legitimación de la obra de arte: institución (principalmente el museo), la crítica (en revistas especializadas y por parte de la Academia) y el mercado. En nuestro caso, habrá que estudiar si es una cuestión únicamente de legitimación del diseño y preguntarnos también si este arte desmaterializado no reclama procesos y metodologías diferentes de las heredadas de una concepción objetual, desarrolladas bajo la idealización de la creación artística como algo meramente subjetivo y desinteresado.

Respecto a esta legitimación, en las dos últimas décadas han reinado diseñadores como Philippe Starck mientras las instituciones artísticas "naturalizaban" la presencia en sus salas de diseñadores como Giorgio Armani o Milton Glaser. Por otra parte, es importante recordar que esos diálogos y transferencias que son frecuentes hoy día, ya lo eran en la Bauhaus o cuando Elsa Schiaparelli unía moda y surrealismo, o Sonia Delauny llevaba la abstracción a otros terrenos. Por no hablar del gran elenco de artistas que trabajan con medios propios de la moda para reivindicar otras prácticas y formas de ver, como Louise Bourgeois o Elena del Rivero, dentro de esa gran obsesión del arte del último medio siglo que es la identidad, donde las reivindicaciones para cambiar los modos de ver -y así transformar los modos de hacer- tienen una dimensión práctica indudable.

En efecto, las transferencias del mundo del diseño al artístico y viceversa son cada vez más frecuentes, mientras se constataba el creciente interés sobre el sistema del diseño por parte de pensadores como Roland Barthes o Gilles Lipovetsky. Todo ello es consecuencia de una disolución de los límites entre disciplinas, cada vez más presente en las prácticas artísticas, pero sobre todo en el papel que lleva a cabo el diseñador como "conector" de distintas realidades y sensibilidades, de las sociales a las productivas.

Por otro lado, y para insistir en el destierro del "desinterés" como algo propio del arte actual, es evidente que en el mismo se han asentado movimientos con una praxis fuerte y una funcionalidad en nuestra sociedad, vinculado con frecuencia a la lucha por valores emergentes; por ejemplo, los defendidos por diversos multiculturalismos. Esto implica que no habría una distancia tan grande con una "utilidad" (social, política...), por no hablar del rechazo del artista como genio romántico, sobre todo cuando se trata de piezas colectivas o participativas, lo que, en su conjunto, deja como obsoleta la idea de arte como una esfera aparte de la realidad y vinculado a una concepción únicamente objetual.

Para responder a este panorama, cada vez es más frecuente hablar en términos de la obra como "proyecto", que imagina racionalmente unos resultados y está abierta a la colaboración y el cambio. Así lo ha demostrado Claire Bishop, quien ya constató la creciente importancia del concepto "proyecto" en artes visuales -ligado también al comisariado y la exposición como procesos de investigación- a partir de 1989, como demuestran casos como la Documenta de Kassel o el Proyecto Escultórico de Münster. ${ }^{24}$

Un ejemplo expreso de ello es la obra de Antoni Muntadas, quien ha teorizado

23 Lippard, L.R. 2004.

24 Bishop, C. 2016, cap. 7. 
sobre la necesidad de estructurar metodológicamente el proceso artístico para llegar a resultados plausibles, insistiendo en el carácter procesual y contextual de la obra, que no queda reducida a condición objetual:

El concepto de "proyecto" irrumpe como forma de trabajo en el lenguaje artístico contemporáneo en el momento en el que se inicia a concebir el desarrollo de una obra en estrecha relación con un contexto. La especificidad del lugar como materia (contexto como materia), la importancia de la temporalidad y de la duración de un proceso de pensamiento, y el rechazo del objeto como finalidad y producto artístico requieren necesariamente una estructura a través de la que dar forma a las cuestiones que han surgido como imperativos en el cambio sucedido al final de los años sesenta y setenta. ${ }^{25}$

Observar las fases que establece Muntadas nos remite a una metodología que, si bien es bastante diferente de otras como las del Design Thinking, entra en la misma lógica que sitúa el "proyecto" como forma de trabajo central para el desarrollo de procesos artísticos, sobre todo de aquellos más complejos, que implican fases de investigación y contemplan la intervención de diversos agentes en momentos distintos de su desarrollo.

Se observa pues que el problema quizás no sea disciplinar, sino que está ligado a una lógica objetual. Cuando nos liberamos de ella, se valoran otras dimensiones del diseño con las que tienen una mayor afinidad los denominados "nuevos comportamientos artísticos" 26 de la última mitad de siglo. Pero no todo vale, o se corre el riesgo de que cualquier imagen sea considerada artística o se relativice la función del proyecto.

Al respecto, el contexto es fundamental, pues determina estatus y valor, al margen de seguir contando con un juicio puramente estético. No obstante, la discusión podría establecerse -más allá de distinciones disciplinarias- en torno a los criterios para establecer cuándo un proyecto es logrado o no, consideración que normalmente se tiene en un ámbito estético, pero que, precisamente por su dimensión práctica, conviene matizar a través de distintos niveles de análisis, para evitar que se privilegie un único punto de vista.

Para ello, hacen falta referencias que sirvan para establecer criterios de valoración. Dentro de la larga tradición proyectual, hay varios que establecen el horizonte del buen diseño a partir de unas premisas. Probablemente el más equilibrado es el famoso Diez principios del buen diseño, elaborado por Dieter Rams en 2003:

1. El buen diseño es innovador.

2. El buen diseño hace útil a un producto.

3. El buen diseño es estético.

4. El buen diseño ayuda a entender un producto.

5. El buen diseño no molesta.

6. El buen diseño es honesto.

7. El buen diseño es duradero.

8. El buen diseño es minucioso hasta el último detalle.

9. El buen diseño se preocupa por el medio ambiente.

10. El buen diseño es tan poco diseño como sea posible. ${ }^{27}$

25 Muntadas, A. 2013, p. 3. El método: preguntas - tipologías - investigación - forma - presupuesto - calendario - desarrollo - feedback.

26 Marchán Fiz, S. 2009.

27 Cit. en Palazuelos, F. 2015. 
Este manifiesto muestra una serie de consideraciones que van más allá del privilegio de lo funcional sobre lo estético, a la luz de muchos años de experiencia y la necesidad de incluir sensibilidades sociales, como la medioambiental. Esto implica, entre otras cosas, que la creación de algo nuevo atañe a formas, usos y procesos, siendo una reflexión que, si bien podemos encontrar en más ámbitos, es cierto que ha adquirido más centralidad en las tradicionales disciplinas de la cultura del proyecto, como la arquitectura y el diseño. No obstante, se sigue hablando desde una lógica objetual.

Para ir más allá de la misma, se debería juzgar si la obra funciona en estos niveles:

- Uno de carácter práctico, que actúa sobre el mundo cotidiano, incluida su capacidad comunicativa y simbólica. En este nivel se atendería a la función social y política del proyecto, considerándose el valor moral y cognitivo del mismo. Por tanto, en este ámbito el espectador es considerado como usuario, es decir, se le supone una capacidad de acción además de percepción, actuando como ciudadano y consumidor.

- Un análisis de tipo epistémico, es decir, concebido como un fenómeno que debe ser descrito y explicado, y que afectaría a los recursos expresivos empleados, moviéndose pues en un ámbito principalmente formal, por lo que concierne al valor estético del proyecto. Aquí el usuario es espectador, pero también parte del proceso de construcción y difusión de la obra.

Se establece así la necesidad de separar el análisis en varios niveles para afirmar si se trata de un proyecto logrado en ambos aspectos. De esta manera, el valor del proyecto se juzga en cada ámbito, sin predominio de uno solo, estudiando también la correspondencia entre ambos, más allá de principios limitantes como función-forma, que hace depender la segunda de la primera. Teniendo en cuenta este análisis por niveles y la validación del proyecto de forma holista, las metodologías que vienen del mundo de la cultura del proyecto podrían aparecer como las pertinentes para responder a la experiencia actual de la realidad, estableciéndose entonces el paso contrario al punto de partida, es decir, la cultura del proyecto pasaría a ser la idónea también para los procesos artísticos contemporáneos, sobre todo aquellos que se definen por su investigación y por albergar una praxis social entre sus objetivos. Para comprobar si esto es posible, habrá que empezar por describir cuáles son las características del período actual y los desafíos que establece.

\section{Hacia nuevas realidades del diseño \\ El diseño de las sociedades postindustriales}

Se ha observado cómo el estatus del diseño (en sus diversas facetas) es definido en un primer momento por contraste con otras disciplinas, principalmente las artes visuales, al mismo tiempo que es ubicado dentro de una cultura del proyecto aún bajo una lógica objetual. ¿Se puede seguir hablando en estos términos hoy?

Bruce Mau, entre otros, ya anunció una nueva concepción de la misión del diseño: en la era de la globalización esta disciplina debería emanciparse de su producto para convertirse en sistema de pensamiento, o más bien actitud, pasando a ser el arte de organizar los recursos: hallar soluciones adecuadas y sostenibles a problemas a gran escala. ${ }^{28}$ Esto implica pensar no solo en un objetivo, sino sobre todo en los procesos que nos llevan al mismo, concibiendo unas formas de trabajo en las que la interdisci- 
plinariedad y la experiencia de grupo no son meras retóricas, sino la verdadera esencia de las dinámicas dentro de este nuevo paradigma.

En este contexto Mau llega a proclamar la necesidad del triunfo de la "clase creativa", que se atreve a imaginar íntegramente el mundo por habitar. Más allá de esta dimensión ideológica, destaca su alejamiento de una lógica objetual. Esto conduce a lo que se podría denominar la "desmaterialización del diseño" en las sociedades postindustriales, en correspondencia con el citado diagnóstico de Lippard, pero sobre todo relacionado en el ámbito específico del diseño con otro tipo de prácticas laborales y su aplicación a otros campos de acción totalmente ajenos a la "producción" en sentido clásico.

Respecto a lo que supuso para el arte a finales de los sesenta e inicios de los setenta, este paso no parece que venga acompañado por la necesidad en primer plano de escapar a los mecanismos tradicionales de legitimación o reconocimiento, pues se mueve con comodidad en espacios híbridos e indefinidos. Sin embargo, sí hay que destacar que reclama cada vez más la idea de "proyecto", como condición estructural, que llevará progresivamente a una "desmaterialización" del diseño, debido sobre todo a los siguientes factores:

- La mencionada enfatización de la importancia de su carácter procesual.

- La centralidad de la dimensión comunicativa en la sociedad.

- La aparición de ramas no objetuales como el diseño de servicios o el diseño estratégico.

- La centralidad de instrumentos y procesos digitales, que suponen un condicionamiento fundamental comparable al que ejerció la máquina para los primeros diseños.

Se insistirá en estos factores para determinar los tipos de diseño que esto genera y sus implicaciones ontológicas, pero antes se debe delimitar mejor el contexto histórico de estas sociedades postindustriales. Un pensador que lo explicó con lucidez fue Michel Serres, con su magno proyecto Le messager, iniciado en 1967. En pocas palabras, Serres constató un giro epocal, y lo manifestó a través de una imagen: estamos asistiendo al paso de la era de Prometeo a la de Hermes, es decir, del mundo de la producción y el industrialismo al de la comunicación. El filósofo francés pensó, a la vez que McLuhan, el orden complejo y móvil de la multiplicidad internacional, lo que le llevó a reconocer la importancia de la comunicación en el corazón de las transformaciones sociales.

Este predominio de Hermes no solo deja atrás a Prometeo, sino también a la estable Hestia, la diosa protectora del hogar en Roma, que estaba en el centro del ámbito doméstico, mientras Hermes regulaba los intercambios con el exterior. Hoy Hermes es el que habita el eje central de la casa y domina la situación. Por ello, este dios inestable y protector de comerciantes es elocuente para describir la transición acaecida en los últimos 50 años, un período de continua aceleración marcado también por el progresivo predominio de lo financiero sobre lo productivo. ${ }^{29}$

Hermes se convierte así en el dios protector del mundo postindustrial, donde para poder pensar la innovación (descubrimiento + aplicación) en la comunicación, hay que abordarla desde una superposición de redes, nodos de conexión en los que "solamente el sujeto errante, móvil, y no fijo, tiene alguna posibilidad de percibir la red en cuanto tal". ${ }^{30}$ 
Este diagnóstico lo completa de nuevo Bruce Mau, en este caso con el Manifiesto incompleto para el crecimiento, donde van apareciendo unos modos y lenguajes que se han normalizado en las dos últimas décadas, reconociéndose de forma generalizada que es difícil hablar de "innovación" si no la asociamos a "colaboración". ${ }^{31}$ En esta situación el diseño aparece como plataforma estratégica, un nuevo Hermes que se convierte en motor económico, fomentando el diálogo entre diferentes disciplinas y entornos creativos, sociales y empresariales.

Pero lo más importante de Manifiesto de Mau es apreciar cómo la incompletitud invita a la acción, a la creación de nuevos lenguajes, a la experimentación y a la colaboración. Y esto lleva al diseño a asumir con menos reparos que otras disciplinas la evolución en los modos de hacer y de relacionarnos que nos conducen hacia una cultura de la participación, representada por un modelo en red.

Para entender la dimensión colaborativa, una buena piedra de toque es Design, when everybody designs, ${ }^{32}$ donde Manzini afirma que nuestra situación actual requiere una nueva "cultura del diseño", pues venimos de una economía de sustitución de objetos, que no es sostenible y que no corresponde con las nuevas formas de creatividad. En efecto, las comunidades creativas y la forma de funcionar en network han sido dos de las preocupaciones de Manzini, y en este libro estudia el diseño como un fenómeno democratizado en un mundo conectado y sometido a un frenético cambio. Actualmente todos diseñan, gracias a las herramientas a disposición y la posibilidad de estar comunicados globalmente, desarrollando soluciones a problemas, que son compartidas dentro de una gran comunidad. Este "diseño difuso" debe dialogar con el "diseño profesional", siendo en el "co-diseño" donde frecuentemente se encuentran, interactuando para conseguir resultados innovadores. En suma, nos remite a pensar en qué términos se plantea una "cultura de la participación". ${ }^{33}$

\section{Aparición de nuevos tipos de diseño}

Para entender hoy qué creatividad puede surgir de esta cultura, puede ilustrar sus posibilidades una famosa exposición de 1956: This is Tomorrow, de la que ha quedado como obra más célebre ¿Qué es lo que hace los hogares de hoy tan diferentes, tan atractivos? de Richard Hamilton. Esta pieza exhibe imágenes apropiadas del universo de la comunicación de masas, anuncios que prometen una vida mejor, destinados a un sujeto reducido a su condición de consumidor y donde el interior burgués no se diferencia ya del mundo mediático. Todo es objeto de contemplación en esta realidad que ha devenido dinámica, espectacular, deseosa de bienestar, mientras se vacían identidades bajo el signo de la homogeneización global.

Esta descripción de una realidad reducida a repetición mediática está precisamente en línea con la época de Hermes recién descrita, pero lo realmente relevante para generar innovación aparece en el inicio del catálogo de la exposición: la muestra surge como fruto de la colaboración entre arquitectos, pintores y escultores para construir el programa del futuro. Se opone así a la especialización de las artes para reivindicar

32 Manzini, E. 2015.

33 Valdés Marín, I. 2014. 
la creatividad surgida de un impulso multidisciplinar y dialogante. ${ }^{34}$ Por ello, más allá de estériles debates sobre las diferencias entre arte y diseño, cabe apreciar un modo de proceder orientado a espacios de encuentro como This is Tomorrow, y que el mundo del diseño ha hecho suyos, precisamente por asumir con menos reparos el desarrollo de los modos proyectuales y la evolución hacia un modelo en red colaborativo.

Y toda red necesita un proceder. Entre todos los posibles, uno de los más importantes a la hora de profesionalizar el diseño en los últimos años y convertirlo en una plataforma estratégica de contacto e intercambio entre distintas realidades (necesidades sociales, producción empresarial, instituciones...) es el Design Thinking. ${ }^{35}$

Con la finalidad de integrar lo que es atractivo desde un punto de vista humano con lo que es tecnológicamente posible y económicamente viable, los diseñadores han sido capaces de crear los productos de los que disfrutamos hoy día. El Design Thinking es el siguiente paso, donde ponemos estas herramientas en las manos de personas que nunca pensaron en sí mismas como diseñadores y así poder aplicar estas herramientas a un abanico de problemas considerablemente más grande. ${ }^{36}$

En términos generales, el Design Thinking ha aportado metodologías -de las que se ha hecho un uso y abuso en los últimos años-que se aplican a los procesos de diseño, a través de una serie de ejercicios que atienden el punto de vista del usuario para darle un mejor servicio y que suelen desarrollarse en varias fases bajo una concepción cíclica: contexto (insights) - ideación - concepto (propuesto por empresas como Fjord) o inspiración - ideación - implementación (en casos como Soulsight), ${ }^{37}$ aunque básicamente son muy parecidos y orientados a comprender el contexto y, en función del mismo, generar ideas y soluciones que son prototipadas y probadas.

Directamente relacionado con el Design Thinking hay otro concepto esencial: el "user-centered design", ${ }^{38}$ del que derivarán otros como "experiencia de usuario" y "service design", que desplazan el foco de atención, situando al usuario y su experiencia en el centro de las diversas fases del proceso de desarrollo del proyecto.

Como se puede deducir, el usuario es también el protagonista de ese diseño difuso del que habla Manzini. Esto invita a reflexionar sobre el verdadero giro: la citada tendencia a una cultura de la participación, que, en realidad, afectará a todos los procesos cotidianos; procesos en los que el mundo del diseño se ha posicionado con meridiana centralidad, y que destierran -quizás ahora de forma decisiva- la creencia en un único autor demiúrgico.

Como resumen de todos estos cambios, se puede entender el tránsito vivido por el mundo del diseño de la siguiente forma: se ha producido una evolución de un diseño tradicional, caracterizado por dar forma (crear cosas) y ser una herramienta para solucionar problemas a partir de oficios individuales y exclusivos, a otro escenario donde el diseño es entendido de manera procesual y como forma de pensamiento, es inclusivo (con la presencia de un usuario co-creador y participativo), donde los modos de trabajo tradicionales se orientan ahora a resolver problemas generando nuevas dinámicas, y

\footnotetext{
34 Alloway, L. 1956, pp. 7-8.

35 Aparecido por primera vez en Brown, T. 2008.

36 Ídem, 2009. Cit. en Díaz Schiavon, A. 2016.

37 López, J. 2011. Medina, P. 2015, pp. 120 y 240-243.

38 Norman, D.A. y Draper, S.W. 1986.
} 
esto es llevado a cabo por medio de equipos de trabajo multidisciplinares con habilidades y actividades transversales. Por tanto, se trata de un modelo en red que potencia los procesos transversales y colaborativos.

Este panorama conlleva romper muchas convenciones afianzadas en nuestra sociedad, con frecuencia basadas en un sistema compuesto por compartimentos estancos. En este contexto se produce una "desmaterialización" del diseño, entendida de varias formas:

- Ligada a formas de diseño que no producen ya objetos sino servicios, estrategias o metodologías.

- Vinculada a la irrupción disruptiva de la tecnología digital, que propicia un trabajo puramente online o a medio camino entre el mundo virtual y el físico.

Este último caso adivina una deriva interesante: el diseñador crea únicamente una idea y su forma (un proyecto que de inicio solo existe digitalmente) y más tarde el usuario podrá personalizarlo y producirlo por medio de impresoras $3 \mathrm{D} u$ otros instrumentos propios de un fab lab, dentro de una lógica común donde se comparte el conocimiento. Se trata de esa tercera revolución industria $1^{39}$ basada en el paso a una manufactura digital y que ha generado el movimiento maker, que plantea una nueva forma de entender la distancia entre idea y realización, ya existente en el diseño industrial, pero cuya personalización por parte del usuario suscita nuevas consideraciones sobre las ideas de "autoría", "versión" y "ejecución" del diseño original.

Así, en el panorama actual se pueden establecer grosso modo 3 grandes grupos simultáneos en los que identificar tipos de diseñadores y diseño:

- Tradicional, ligado al producto físico, bien en serie o en colaboración con artesanos. Este último vive un nuevo renacimiento por sus posibilidades formales y por la valoración del producto como objeto único. En general, sus procesos son los propios del diseño objetual habitual, pero puede incorporar en algún paso procesos digitales y colaborativos, aunque son instrumentales y no estructurales.

- Desmaterializado y, por tanto, no ligado a una lógica objetual, donde la tecnología es entendida de forma instrumental y no estructural. Es el caso del diseño organizacional/relacional (diseño de servicios, management design, diseño de sistemas, diseño estratégico), o la teoría en torno al diseño y las metodologías que ofrece (Design Thinking, Design Sprint, Scrum...), que en términos generales se sirve del diseño como lenguaje y plataforma de conexión entre distintos sectores, de ahí que las dinámicas colaborativas y en red sean su ámbito habitual.

- Desmaterializado y radicalmente marcado por la tecnología. No solo abarca el uso cotidiano y básico de herramientas digitales, o trabajar en entornos digitales (animación, interacción, interfaces, realidad aumentada, realidad virtual...), sino también las actividades que se desarrollan en relación con procesos de big data y su visualización, inteligencia artificial, machine learning, robótica, blockchain... ${ }^{40}$

En su conjunto, se apunta a un cambio de paradigma, incluso en los casos más tradicionales, puesto que el valor del producto no depende tanto de su concepción como objeto terminado y autónomo, sino de todo el proceso que le concierne, tanto de producción como de vida. Además, el diseño -igual que ocurre en otros muchos ámbitos

39 AA.VV. 2012

40 Esta clasificación surge en diálogo con Javier Maseda, Director del Digital Design Lab del IED Madrid. 
creativos- cada vez se relaciona y proyecta en ámbitos más desmaterializados, fruto tanto de sus derivas teóricas y conceptuales como de su dependencia de la tecnología y de la creación de nuevas formas de comunicación y comercio derivadas de ella.

De esta manera, se va imponiendo la visión del diseño como agente transformador del mundo, cuya eficacia y capacidad de respuesta a los cambios tecnológicos y sociales se extiende a otros ámbitos creativos. Todos ellos se orientan, en suma, a crear realidad, conscientes de los incesantes cambios que vuelven rápidamente obsoletos muchos discursos implantados durante décadas.

\section{Hacia un nuevo paradigma}

Como es evidente, los parámetros para valorar un proyecto están cambiando y también el alcance de productos y proyectos. En gran parte, porque hoy se realiza el sueño de Paul Valéry de "conquistar la ubicuidad", ${ }^{41}$ mientras se adivinan numerosas derivas procedentes del mundo digital, que supondrán consecuencias en la producción, distribución, autoría y comercialización de cualquier proyecto. En definitiva, igual que la época de la máquina condicionó una estética y unos procesos en diseño, la época digital marca el trabajo del diseñador actual para que pueda generar servicios y nuevas soluciones prácticas y de comunicación.

Como en toda revolución, siempre habrá apocalípticos e integrados a favor de las nuevas tecnologías, pero es patente la actual influencia de la tecnología y las posibilidades que abre, sobre todo si es considerada como medio y se amplía la reflexión al marco de problemas en los que deberá intervenir.

Entre los nuevos fenómenos que esto está generando -y posibles procedimientos pertinentes para este nuevo paradigma-, se halla lo que Pierre Lévy denominó "inteligencia colectiva" 42 y que hoy estudian investigadores como Thomas Malone. De una forma muy general, se entiende por "inteligencia colectiva" la capacidad de pensar juntos gracias a una colaboración ordenada y respetuosa de los individuos, resultando básico que estos aporten experiencias diferentes y complementarias, que permitan un enriquecimiento cognitivo. En estos matices reside la diferencia frente a su origen en la biología, que ha observado este tipo de inteligencia en comportamientos de animales como abejas u hormigas. Esta dimensión ha dado ahora un salto cualitativo gracias a Internet y las posibilidades de comunicación y organización que facilita.

En esta línea, se identifican algunas de las características que debería cumplir esta cultura participativa para una producción más eficaz de innovación: debería ser abierta, peering (intercambio transversal de competencias), compartida y de acción global. ${ }^{43}$ Hay muchos ejemplos que demuestran su validez en diferentes ámbitos y escalas, como las citizen sciences; por ejemplo, cuando aficionados colaboran para identificar galaxias, o programas para construir escenarios plausibles de la evolución del planeta, como el Millennium Project.

Pero la ciencia exige garantías. ¿Un procedimiento como este es suficientemente fiable y avanza en el conocimiento? Hay un dato significativo para el desarrollo de metodologías en este sentido: los distintos participantes deben ser complementarios,

41 Valéry, P. 1928.

42 Lévy, P. 2004

43 De Biase, L. 2016. 
llegando a conclusiones argumentadas y fundadas, y no ser únicamente la suma de opiniones y gustos. Este espacio común de distintos agentes se puede hallar estructurado en plataformas, cuyas reglas de juego pueden cambiar radicalmente el resultado, pasando de un sistema cuantitativo de mayorías a uno "consensuado". Es decir, los participantes se corrigen entre sí en un proceso no cuantitativo, o de voto, sino en la búsqueda de consenso dentro de la comunidad. Sin duda, esto abre otras posibilidades nada despreciables, aunque aplicadas, por ejemplo, a grupos de investigación, plantean otras consideraciones como la escala en la que es más eficaz, lo que probablemente limita su implantación.

Solamente con apuntar uno de los fenómenos que puede propiciar la deriva digital, se adivinan las posibilidades de este cambio de paradigma y las experiencias a las que habrá que dar respuesta y forma. Es precisamente el mundo del diseño uno de los que parece más cercano y permeable a este panorama, por su flexibilidad y transversalidad, además de haber asumido varios de las consecuencias ya citadas y que son fundamentales en este paradigma: la enfatización de procesos colectivos y del rol activo del usuario dentro de los mismos; de ahí la dificultad para hablar de un único autor y la asunción de la condición desmaterializada y abierta del diseño. Por tanto, hay que reconsiderar una vez más las prácticas en torno a la creatividad y los criterios para establecer qué es un diseño logrado, como se ha planteado al final del primer capítulo; y, por supuesto, ir más allá de un concepto unívoco de funcionalidad y de categorías como la belleza o la validez universal de una eficacia emocional.

Necesitamos pues nuevos lenguajes para nuevas experiencias que permitan considerar ética, política y comunicativamente el nuevo contexto global, reescribiendo así las constelaciones de intereses de los sistemas consolidados. La asunción radical del diseño como proceso va en esta línea, habiendo propiciado en las dos últimas décadas un territorio híbrido y multidisciplinar donde surge buena parte de la innovación. Se trata pues de destacar la idea de "proyecto", lo que significa "imaginar" -en el sentido de Hilary Putnam- otro mundo, es decir, realizar una proyección racional para calcular la manera más adecuada para alcanzar el resultado deseado. ${ }^{44}$

Esto implica la necesidad de establecer estrategias y análisis de sistema para determinar la viabilidad y el valor de un proyecto y, sobre todo, para fomentar modos de pensamiento más allá de los necesarios conocimientos técnicos, anclados en muchos casos aún en un mundo objetual. Y todo ello sin olvidar -como explicó Francisco Jarauta en el I Encuentro de Innovación Académica- que "toda reflexión sobre el diseño termina siendo una reflexión sobre las tendencias de la cultura y sus proyectos". ${ }^{45} \mathrm{Se}$ abre entonces un interesante campo de experimentación donde realidades locales y globales se encuentran en intersecciones abiertas, un novum donde el diseño tendrá un papel central.

\section{Bibliografía}

Alloway, L. 1956. "Design as a Human Activity". Crosby, Theo (ed.). This is Tomorrow. Londres: The Whitechapel Art Gallery. Argan, G.C. 2010. Lo artístico y lo estético. Madrid: Casimiro, (1973).

44 Putnam, H. 1990, p. 129

45 Francisco Jarauta, Presentación del I Encuentro de Innovación Académica: El futuro de la enseñanza del diseño, Madrid, Istituto Europeo di Design, 27/05/2014. 
Benjamin, W. 1992. "La obra de arte en la era de su reproductibilidad técnica". Pp. 17-59 en ídem. Discursos interrumpidos I. Madrid: Taurus, (1935).

Bishop, C. 2016. Infiernos artificiales. Arte participativo y politicas de la espectaduría. Taller de Ediciones Económicas, (2012).

Bonami, F. (ed.) 2008. Italics. Arte italiana fra tradizione e rivoluzione 1968-2008. Milán: Mondadori Electa.

Brown, T. 2008. "Design Thinking”. Harvard Business Review, junio 2008. https://hbr. org/2008/06/design-thinking [accedido el 25/05/2019].

—, 2009. Change by Design, How Design Thinking Transforms Organizations and Inspires Innovation, Nueva York: Harper Collins.

Cerritelli, C. (ed.) 2017. Bruno Munari. Artista totale. Turín: Fondazione Ettore Fico.

Chomsky, N. 2017. Réquiem por el sueño americano. Los diez principios de la concentración de la riqueza y el poder. Ciudad de México: Sexto Piso.

De Biase, L. (ed.) 2016. L'intelligenza colletiva. Come funzionano le reti di informazioni e che cosa ci possiamo fare. Colección nòva-edu, Lezioni di futuro, Il Sole 24 ore, $25 / 02 / 2016$.

Díaz Schiavon, A. 2016. "El nuevo perfil del diseñador", en Jarauta, F. y Medina, P. (eds.). Cuadernos de Diseño 5: Pedagogías. Madrid: Editorial IED. https://iededitorial.com/editorial/cuadernos-de-diseno-5/

Dorfles, G. 1959. Il divenire delle arti. Turín: Einaudi.

, 1962. Simbolo, comunicazione, consumo. Turín: Einaudi.

, 2006. "La ambigua relación entre arte y diseño". Pp. 23-29 en Jarauta, F. (ed.): Cuadernos de Diseño 2: Arte y Diseño. Madrid: Editorial IED.

- 2010. Design. Percorsi e trascorsi. Cinquant'anni di riflessioni sul progetto contemporaneo. Milán: Lupetti.

Infante del Rosal, F. 2018. La autonomía del diseño. Diseño como categoría estética. Valencia: Universitat de València.

Jarauta, F. 2006. "Presentación". Pp. 11-19 en ídem (ed.): Cuadernos de Diseño 2: Arte y Diseño. Madrid: Editorial IED.

Kant, I. 1977. Crítica del juicio. Madrid: Espasa Calpe, (1790).

Lévy, P. 2004. Inteligencia colectiva. Por una antropología del ciberespacio. Washington D.C.: Organización Panamericana de la Salud. http://inteligenciacolectiva. bvsalud.org/public/documents/pdf/es/inteligenciaColectiva.pdf [accedido el 01/05/2019].

Lippard, L.R. 2004. Seis años: la desmaterialización del objeto artístico. De 1966 a 1972. Madrid: Akal, (1973).

López, J. 2011. "Design thinking: metodología para la innovación”. EOI, 15/03/2011. http://www.eoi.es/blogs/fdi/2011/03/15/design-thinking-metodologia-para-la-innovacion/\#sthash.FllPenEt.dpuf [accedido el 13/05/2019].

Manzini, E. 2015. Design, When Everybody Designs. An Introduction to Design for Social Innovation. Cambridge (Massachusetts) - Londres: MIT Press.

Marchán Fiz, S. 2009. Del arte objetual al arte de concepto. Madrid: Akal, (1972).

Mau, B. 1998. An Incomplete Manifesto for Growth. 1998. http://www.manifestoproject. it/bruce-mau/ [accedido el 11/05/2019].

, 2004. Massive Changes. Londres: Phaidon.

Mecacci, A. 2012. Estetica e design. Bolonia: il Mulino.

Medina, P. 2014. "Introducción", en Jarauta, F. y Medina, P. (ed.). Cuadernos de Diseños 
4: Diseño de procesos. Madrid: Editorial IED. https://iededitorial.com/editorial/ cuadernos-de-diseno-4/

— 2015. Nueva economía 20+20. Economía del Diseño. Madrid: Fundación EOI.

Millennium Project. http://www.millennium-project.org [accedido el 09/05/2019].

Munari, B. 1971. Artista e designer. Bari: Laterza.

, 1977. Fantasia. Invenzione, creatività e immaginazione nelle comunicazioni visive. Bari: Laterza.

Muntadas, A. 2013. Riflessioni per una metodologia del progetto. For A Project Methodology. Venecia: Monos.

Norman, D.A. y Draper, S.W. 1986. User Centered System Design. Nueva York: Hillsdale.

Norman, D.A. 2005. El diseño emocional. Por qué nos gustan (o no) los objetos cotidianos. Barcelona: Paidós.

Palazuelos, F. 2015. Los principios del "buen diseño" de Dieter Rams. https://hipertextual.com/2015/01/los-principios-del-buen-diseno-dieter-rams [accedido el 05/05/2019].

Putnam, H. 1990. "The Craving for Objectivity". Realism with a Human Face. Cambridge, MA: Harvard University Press.

Ramírez, J.A. 1997. Medios de masas e historia del arte. Madrid: Cátedra.

Read, H. 1961. Arte e industria: principios del diseño industrial. Barcelona: Infinito.

Sennett, R. 2009. El artesano. Barcelona: Anagrama, (2008).

Serres. M. 2014. Il messaggero. Pp. $42-54$ en Polizzi, G. y Porro, M. (ed.): "Michele Serres". Riga, núm. 35, (1967).

Simon, H.A. 1996. The Sciences of the Artificial. Cambridge, MA: MIT Press.

Valdés Marín, I. 2014. "Consumir diseño en la era digital", en Jarauta, F. y Medina, P. (ed.). Cuadernos de Diseño 4: Diseño de procesos. Madrid: Editorial IED. https:// iededitorial.com/editorial/cuadernos-de-diseno-4/

Valéry, P. 1928. La conquista de la ubicuidad. https://docgo.net/doc-detail.html?utm_ source $=95748793$-la-conquista-de-la-ubicuidad-paul-valery-pdf $\quad$ accedido el 19/05/2019].

Vitta, M. 2018. "Dall'oggetto all'oggetto. Le radici profonde dell'estetica". Aisthesis. Pratiche, linguaggi e saperi dell'estetico, núm. 11. http://www.fupress.net/index.php/ aisthesis/article/view/14613/13654 [accedido el 19/05/2019].

VV.AA. 2012. "Manufacturing and innovation". Pp. 1-14 en The Economist, 21 de abril de 2012. https://dc.mit.edu/sites/default/files/pdf/Econ\%20Special\%20 Rpt\%20Manufactur.pdf [accedido el 25/05/2019]. 


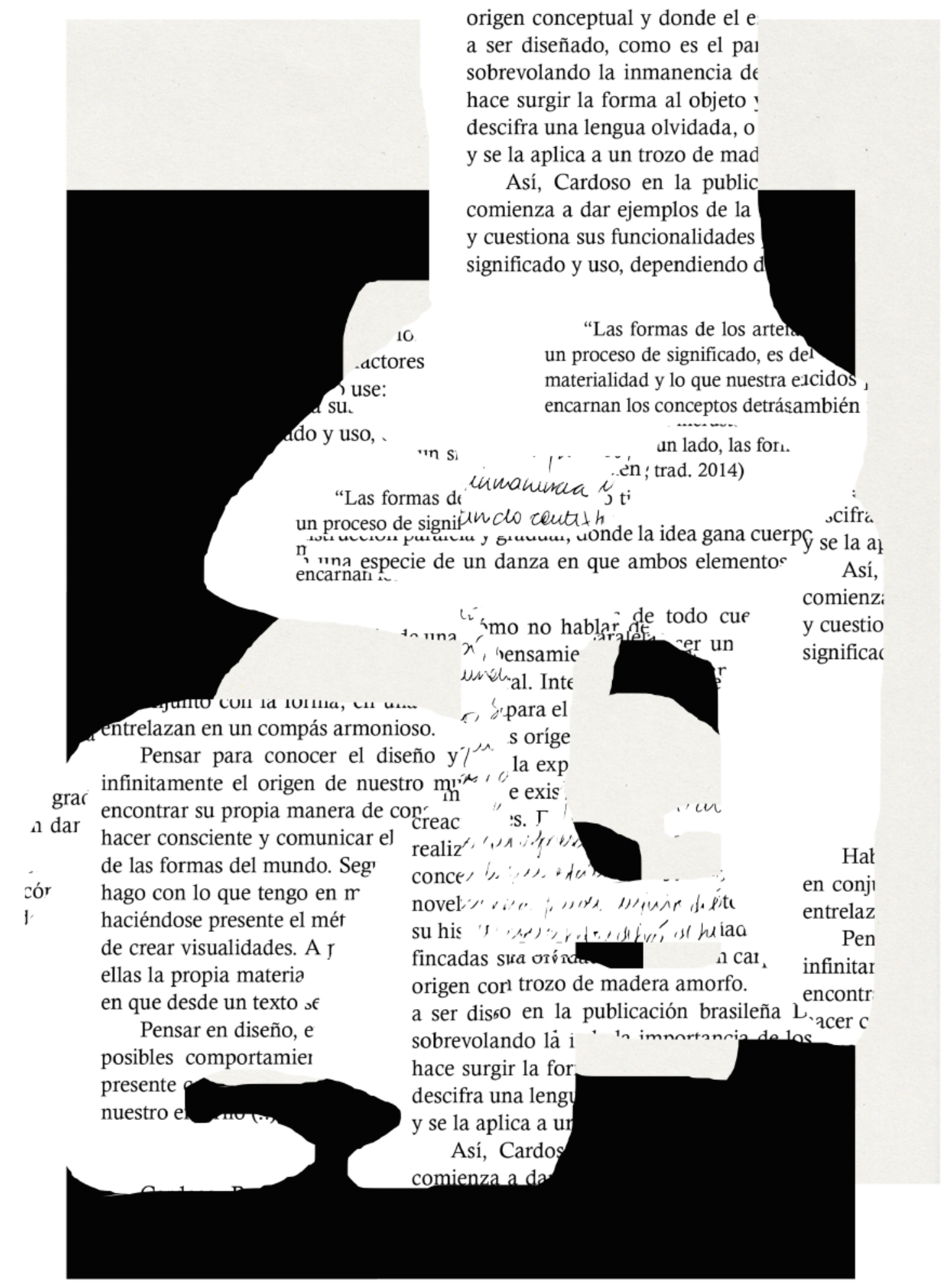

realizar la forma para $\iota_{\text {. }}$

conceptual por las orígenes ،

novela, el objeto, la exposiciór.

su historia, porque existe en el 1

fincadas sus raíces. Desde allí

origen conceptual y donde el e a ser diseñado, como es el pa sobrevolando la inmanencia d hace surgir la forma al objeto descifra una lengua olvidada, 0

Así, Cardoso en la public comienza a dar ejemplos de la y cuestiona sus funcionalidades significado y uso, dependiendo

"Las formas de los arter un proceso de significado, es de materialidad y lo que nuestra eicidos enceptos detrásambién un lado, las for. en; trad. 2014)

\section{"Las formas di}

mona sis "Las foutith , uonde la idea gana cuerp $y$ se la a ina especie de un danza en que ambos elementor Así,

¿' $m o$ no hablar de todo cue $x$, hensamie wén. Inte relazan en un compás armonioso.

conocer el diseño y y cuestio significa en conji ntrelaz

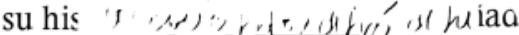
fincadas sura oróncen $n$ cat infinitar ellas la propia materia que desde un texto of encontr: Pensar en diseño, posibles comportamie presente nuestro sobrevolando lả hace surgir la for descifra una lengy y se la aplica a ur

Así, Cardos comienza a d 


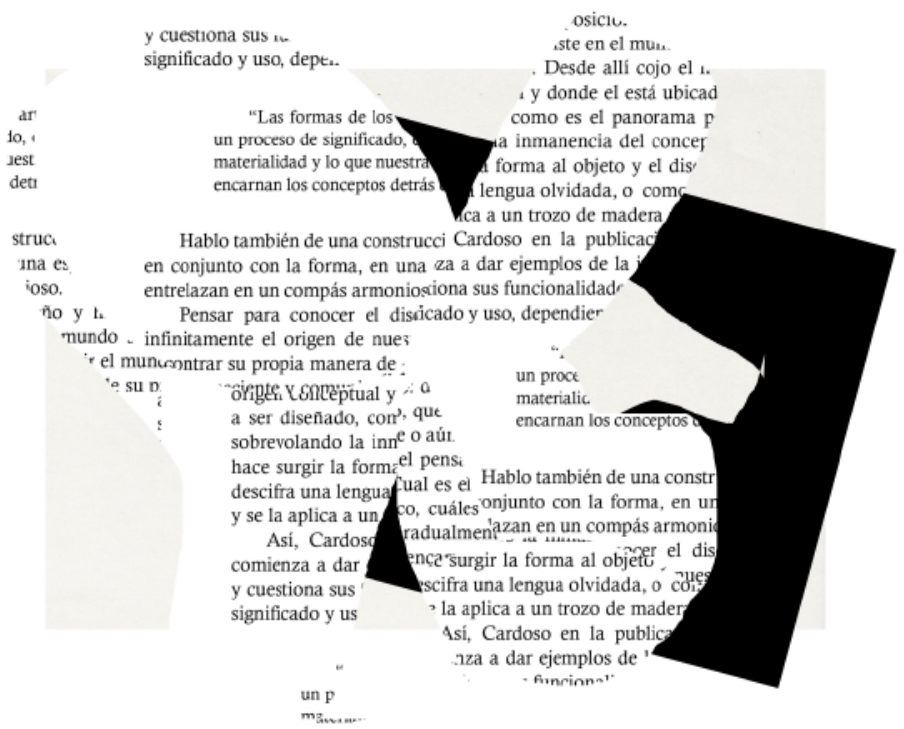

"Lo impreso exige una humildad de espíritu por cuya falta muchas de las bellas artes se tambalean ahora en experimentos de autoconciencia y sensiblería. No hay nada simple ni aburrido en lograr una página transparente. La ostentación vulgar es el doble de fácil que la disciplina".

Beatrice Warde, The Crystal Goblet, or why printings should be invisible (1930)

"El diseño que es objetivo, comprometido con el bien común, bien compuesto y delicado, constituye la base del comportamiento democrático".

Josef Müller-Brockmann, Grid and Design Philosophy (1981) 

EDITA

\section{SEyTA.}

SOCIEDAD ESPAÑLAA
DE ESTETICA Y TEORIA DE LAS ARTES

CON LA COLABORACIÓN DE

\begin{tabular}{|c|c|c|}
\hline 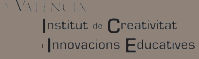 & $\begin{array}{l}\text { VNIVIRSIIA } \\
\text { In VVIIINCI Departament de Filosofia }\end{array}$ & 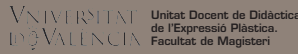 \\
\hline $\begin{array}{l}\text { TitTicA } \\
\text { SoFFA }\end{array}$ & 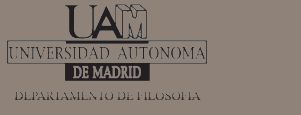 & $\begin{array}{l}\text { UAB } \\
\text { Universitat Autònoma } \\
\text { de Barcelona }\end{array}$ \\
\hline
\end{tabular}

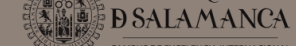

https://ojs.uv.es/index.php/LAOCOONTE/index 